\title{
Characterisation of a highly polymorphic microsatellite at the DXS207 locus: confirmation of very close linkage to the retinoschisis disease gene
}

Claudine Oudet, Chantal Weber, Josseline Kaplan, Bertrand Segues, Marie-Françoise Croquette, Elisabeth Ollagnon Roman, André Hanauer

\begin{abstract}
Juvenile retinoschisis (RS) is an $\mathrm{X}$ linked recessive vitreoretinal disorder for which the basic molecular defect is unknown. The gene for RS has been previously localised by linkage analysis to Xp22.1p22.2 and the locus order Xpter-DXS16(DXS43, DXS207)-RS-DXS274-DXS41Xcen established. To improve the resolution of the genetic map in the $R S$ region, we have isolated a highly polymorphic microsatellite at DXS207, which displays at least nine alleles with a heterozygosity of 0.83 . Using this microsatellite and four other Xp22.1-p22.2 marker loci, DXS16, DXS43, DXS274, and DXS41, we performed pairwise and multilocus linkage analysis in 14 kindreds with $R S$. The microsatellite was also typed in the CEPH (Centre d'Etude du Polymorphisme Humain) reference families. Tight linkage was found between $R S$ and $D X S 207$ $(Z(\theta)=14.32$ at $\theta=0.0), R S$ and $D X S 43$ $(Z(\theta)=8 \cdot 10$ at $\theta=0 \cdot 0)$, and $D X S 207$ and $\operatorname{DXS} 43(Z(\theta)=40.31$ at $\theta=0.0)$. Our linkage results combined with data previously reported suggest that the DXS207-DXS43 cluster is located less than 2 cM telomeric to the RS locus. The microsatellite reported here will be a very useful marker for further linkage studies with retinoschisis as well as with other diseases in this region of the $X$ chromosome.
\end{abstract}

( $($ Med Genet 1993;30:300-3)

$\mathrm{X}$ linked juvenile retinoschisis ( $\mathrm{RS}$ ) is a recessive disorder of the sensory retina resulting in progressive visual impairment. It is the most common cause of macular disease in children and adolescents. ${ }^{1}$ Affected male patients show microcystic degeneration of the retina leading to intraretinal splitting, mainly in the nerve fibre layer. The disease is characterised by marked interfamilial, and even intrafamilial, phenotypic variation. While foveal retinoschisis is present in almost all patients, there is wide variability of expression of the peripheral retinal features. Vision of female carriers is usually normal, but they frequently show peripheral retinal alterations similar to those found in affected males. ${ }^{2}$ Although an abnormality in the Müllerian cells has been suggested, ${ }^{3}$ the basic defect in RS remains unknown. The RS gene has been mapped to Xp22.1-p22.2, between $D X S 274$ on the proximal side and $D X S 207$ and $D X S 43$ on the distal side, closely linked to the two latter markers. ${ }^{24-8}$ This localisation was further supported by data also showing close linkage between $R S$ and two additional Xp22.1-p22.2 polymorphic loci, $D X S 197$ and $D X S 43 .^{4589}$ The latter markers are closely linked to DXS207 and DXS43. ${ }^{1011}$ Despite the variability in the clinical expression of the disease, no evidence for genetic heterogeneity for RS was found. These results have already rendered genetic prediction feasible in many RS families. ${ }^{2}$ A more precise mapping of the RS locus is a prerequisite for positional cloning. Accuracy of genetic mapping, including identification of recombinants which provide crucial information for orienting the gene search, was limited by the lack of highly informative markers in the region of the $\mathrm{RS}$ gene. We have identified a highly informative microsatellite marker at $D X S 207$. Our linkage results suggest that this marker is located less than $2 \mathrm{cM}$ telomeric to the RS locus.

\section{Patients and methods}

PATIENTS

Fourteen unrelated families with $\mathrm{X}$ linked recessive retinoschisis were analysed, seven of which have been used in a previous linkage study reported by Kaplan et al. ${ }^{2}$ The diagnosis was, in each case, confirmed by careful ophthalmological examination. DNA analysis was performed on 181 subjects including 39 affected males.

\section{MOLECULAR STUDIES}

The procedures for genomic DNA extraction, restriction enzyme digestion, gel electrophoresis, Southern blotting, and hybridisation to radioactively labelled probes have been described elsewhere. ${ }^{12}$

PCR amplification of the DXS207 microsatellite was carried out in $25 \mu \mathrm{l}$ with $3 \mathrm{pmol}$ of end labelled primer, $3 \mathrm{pmol}$ of the same unlabelled primer, and $6 \mathrm{pmol}$ of a second unlabelled primer, $200 \mathrm{mmol} / \mathrm{l}$ each dNTP, $50 \mathrm{mmol} / 1 \mathrm{KCl}, 10 \mathrm{mmol} / 1$ Tris- $\mathrm{HCl}$ (pH $8.2), 1.5 \mathrm{mmol} / 1 \mathrm{MgCl}_{2}, 100 \mathrm{ng}$ of genomic DNA, and 1 unit of Taq DNA polymerase (Perkin-Elmer/Cetus). Samples were overlaid 
Table 1 The dinucleotide repeat and flanking sequence. The priming sequences are underlined.

5'-CCCCTCCGGTTCACTCCACATTCTGCCAT

CAGAGTCATTTCTCCGAGACACAGATCTCG

CAGATCTGGTAATTTCACACACACACACAC

ACACACACACACACACACACACACACAC

ACACACACACACCCTCCTCCTCAAGGGCTG

TCAATTTTATACAGATAAACATGGGTTTAA

AGGCTTTCC CTGATC-3

with mineral oil and processed through one step of denaturation $\left(94^{\circ} \mathrm{C}\right.$ for five minutes), followed by 25 cycles of denaturation $\left(94^{\circ} \mathrm{C}\right.$ for one minute), annealing $\left(55^{\circ} \mathrm{C}\right.$ for one minute), and elongation $\left(67^{\circ} \mathrm{C}\right.$ for two minutes), and a last step of elongation (seven minutes at $67^{\circ} \mathrm{C}$ ). One $\mu$ l of each reaction was mixed with $8 \mu$ l of $90 \%$ formamide blue and $3 \mu \mathrm{l}$ of this mix were loaded on a $8 \%$ polyacrylamide- $50 \%$ urea sequencing gel. Gels were run at 1400 volts for four hours and subsequently exposed to Kodak X-AR films for a few hours.

GENETIC LINKAGE ANALYSIS

In addition to the microsatellite polymorphism, six RFLPs, including pXUT23 and pSE 3.2L (DXS16), pD2 (DXS43), pBA4B (DXS207), CRI-L1371 (DXS274), and p99.6 (DXS41) were used in the present study. The probes and conditions are described in Biancalana et al. ${ }^{11}$ Pairwise and multilocus linkage analyses were performed using the LINKAGE program package (version $4 \cdot 8) .{ }^{13} \mathrm{RS}$ was assumed to have complete penetrance, and the allele frequency of RS was taken to be $10^{-5}$. The genotypic data of CEPH (Centre d'Etude du Polymorphisme Humain) families were extracted from the CEPH database version 5.

\section{Results and discussion}

We tested for the presence of a (CA) repeat, a $35 \mathrm{~kb}$ cosmid clone obtained by screening an $\mathrm{X}$ chromosome specific library ${ }^{14}$ with probe pBA4B at DXS207. Hybridisation of an $E c o$ RI restriction digest to a ${ }^{32} \mathrm{P}$ labelled poly(dA.dC).poly(dT.dG) probe showed a strongly hybridising fragment. We directly subcloned a Sau3A digest of the cosmid into a Bluescript vector, and screening of these subclones with poly(dA.dC).poly(dG.dT) resulted in a positive clone which was sequenced. A (CA) 27 repeat was identified and two oligonucleotide primers were synthestised, flanking a region of $117 \mathrm{bp}$ including the (CA) 27 repeat. The repeat and flanking sequence is shown in table 1. Genomic DNA from a set of CEPH family mothers was tested
Table 2 Allele frequencies for the dinucleotide repeat at DXS207.

\begin{tabular}{|c|c|}
\hline Allele (size in bp) & $\begin{array}{l}\text { Allele frequency } \\
\text { (96 chromosomes) }\end{array}$ \\
\hline $\begin{array}{ll}\text { A1 } & (115) \\
\text { A2 } & (117) \\
\text { A3 } & (119) \\
\text { A4 } & (121) \\
\text { A5 } & (123) \\
\text { A6 } & (125) \\
\text { A7 } & (127) \\
\text { A8 } & (129) \\
\text { A11 } & (137)\end{array}$ & $\begin{array}{l}0 \cdot 035 \\
0 \cdot 12 \\
0 \cdot 12 \\
0 \cdot 10 \\
0 \cdot 24 \\
0 \cdot 19 \\
0 \cdot 12 \\
0 \cdot 017 \\
0 \cdot 035\end{array}$ \\
\hline
\end{tabular}

for polymorphisms by PCR amplification of the repeat using the flanking primers, one of which was ${ }^{32} \mathrm{P}$ labelled. Nine alleles ranging in size from 115 to $137 \mathrm{bp}$ were identified (table 2 ). The alleles differ from adjacent ones by one dinucleotide pair, but so far no allele has been detected with product sizes of 131, 133, and $135 \mathrm{bp}$. From observed allele frequencies a heterozygosity of 0.83 was predicted. The combined heterozygosity at $D X S 207$, using the RFLP detected with pBA4B and the new microsatellite, was $90 \%$ in 48 unrelated females.

We have applied this strongly informative polymorphism to linkage analysis in retinoschisis by typing DNA from 14 RS kindreds, seven of which have previously been used in the linkage study reported by Kaplan et al. ${ }^{2}$ In addition, six RFLP markers spanning the $\mathrm{Xp} 22.1-\mathrm{p} 22.2$ region were analysed, including pXUT23 and PSE3.2L (DXS16), pD2 (DXS43), pBA4B (DXS207), CRI-L1371 (DXS274), and p99.6 (DXS41). The results of the two point linkage analysis, which are given in table 3, were obtained using the program MLINK and include the data concerning the seven RS families reported by Kaplan et al. ${ }^{2}$ Analysis at locus DXS207 was found to be fully informative in the 14 families and no recombination event was observed with $R S$. The maximum lod score for $R S-D X S 207$ was 14.32 at a recombination fraction of $0.00(95 \%$ confidence interval of $\theta=0 \cdot 00-0 \cdot 03$ ). Additionally, no recombination was evident in our families between $D X S 43$ and $R S(Z(\theta)=8 \cdot 10$, $\theta=0.00)$. Thus, these data confirm and extend previous findings of close linkage between $R S$ and both $D X S 207$ and $D X S 43.568$ When our data for $D X S 207$ and $D X S 43$ are combined with the data published by these authors, the maximum lod scores between $R S$ and $D X S 207$ and between $R S$ and $D X S 43$ become $Z(\theta)=21.96$ at $\theta=0.01$ and $Z(\theta)=33.40$ at $\theta=0.02$ respectively. The confidence intervals

Table 3 Pairwise lod scores for linkage between $R S$ and five Xp22.1-p22.2 marker loci.

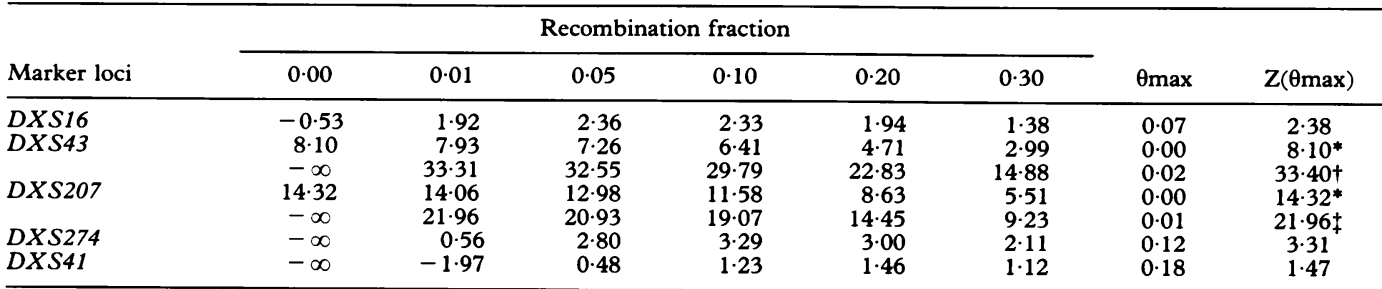

* Data from the present study. $†$ Data from the present study that have been combined with data from Alitalo et al, ${ }^{5} \mathrm{Dahl}$ et al, ${ }^{6}$ and Sieving et al. ${ }^{8} \ddagger$ Data from the present study that have been combined with data from Alitalo et al ${ }^{5}$ 
Table 4 Pairwise lod scores for linkage between DXS207 and four other Xp22.1-p22.2 marker loci in the combined $C E P H$ panel of reference families and $14 R S$ pedigrees.

\begin{tabular}{|c|c|c|c|c|c|c|c|c|}
\hline \multirow[b]{2}{*}{ Locus $v$ locus } & \multicolumn{6}{|c|}{ Recombination fraction } & \multirow[b]{2}{*}{$\theta \max$} & \multirow[b]{2}{*}{$\mathrm{Z}(\theta \max )$} \\
\hline & 0.00 & 0.01 & 0.05 & $0 \cdot 10$ & $0 \cdot 20$ & 0.30 & & \\
\hline $\begin{array}{l}D X S 207-D X S 43 \\
D X S 207-D X S 274 \\
D X S 207-D X S 41 \\
D X S 207-D X S 16\end{array}$ & $\begin{array}{l}40 \cdot 31 \\
-\infty \\
-\infty \\
-\infty\end{array}$ & $\begin{array}{r}39 \cdot 17 \\
18 \cdot 37 \\
6 \cdot 07 \\
30 \cdot 53\end{array}$ & $\begin{array}{l}37 \cdot 10 \\
24 \cdot 75 \\
12 \cdot 19 \\
30 \cdot 29\end{array}$ & $\begin{array}{l}33 \cdot 66 \\
25 \cdot 10 \\
13 \cdot 86 \\
28 \cdot 18\end{array}$ & $\begin{array}{l}26 \cdot 10 \\
21 \cdot 34 \\
12 \cdot 36 \\
22 \cdot 29\end{array}$ & $\begin{array}{r}17 \cdot 62 \\
15 \cdot 07 \\
8 \cdot 85 \\
15 \cdot 25\end{array}$ & $\begin{array}{l}0.00 \\
0.08 \\
0 \cdot 11 \\
0.02\end{array}$ & $\begin{array}{l}40 \cdot 31 \\
25 \cdot 29 \\
13 \cdot 87 \\
30 \cdot 86\end{array}$ \\
\hline
\end{tabular}

obtained from the pooled data for the $R S$ $D X S 207$ and the $R S-D X S 43$ linkage, which are important for diagnosis, were 0.005-0.05 and 0.005-0.06 respectively. At least two crossover events were observed with $D X S 274$ $(Z(\theta)=3.31$ at $\theta=0.12)$ which confirm looser linkage with the closest proximal flanking marker. Combination of our data for DXS274 and those of Alitalo $e t a l$ yields a lod score of 12.20 at $\theta=0.08$.

Linkage relationships between the DXS207 marker locus and four Xp22.1-p22.2 marker loci, including $D X S 16, D X S 43, D X S 274$, and $D X S 41$, were also further investigated using $36 \mathrm{CEPH}$ pedigrees informative at $D X S 207$ and the $14 \mathrm{RS}$ pedigrees from the present study. For the CEPH pedigrees, marker data for the RFLPs identified at $D X S 16, D X S 207$, $D X S 43, D X S 274$, and $D X S 41$ were obtained from the CEPH database. Table 4 gives the results of the pairwise linkage analyses between DXS207 and the four other Xp22.1p22.2 marker loci in the combined CEPH and RS pedigrees. They confirm and firmly support the previously established values. ${ }^{10}$ The marker loci DXS207 and DXS43 showed completely concordant inheritance $(Z(\theta)=40.31$ at $\theta=0.00)$. Previous studies have shown that these two markers are very tightly linked, ${ }^{1011}$ and no recombinations between them have been reported so far.

A multilocus linkage analysis was performed using the LINKMAP program. We used the following map of markers as established by Alitalo et al ${ }^{10}$ : tel-DXS16-1.6-(DXS43, $D X S 207)-8-D X S 274-3 \cdot 5-D X S 41-c e n$. The distance (DXS207,DXS43)-DXS274 was slightly increased to conform with the data we obtained for linkage between these markers. As no recombination between $D X S 207$ and DXS43 was observed, haplotypes for these two markers were constructed and used in multipoint linkage analysis. A maximum multipoint lod score of 16.52 was obtained for $R S$ being at a position corresponding to the cluster $D X S 207-D X S 43$ (figure). The one unit support interval (Zmax-1) was about $4 \mathrm{cM}$ around the DXS207-DXS43 cluster. The absence of recombination between $R S, D X S 207$, and $D X S 43$ in our families did not allow us to infer an order for these loci. However, the few recombinational events detected between $R S$ and both the $D X S 207$ and $D X S 43$ marker loci by Alitalo et $a l^{\top}$ and Sieving $e t$ al ${ }^{8}$ support the localisation of the disease gene on the proximal side of both $D X S 207$ and $D X S 43$. Taken together, the data position the DXS207 locus, tightly linked to the $D X S 43$ locus, less than $2 \mathrm{cM}$ telomeric to the disease gene.

\section{Conclusions}

The identification of the informative microsatellite polymorphism allowed us to assess the genetic distances in $\mathrm{Xp} 22.2$ more accurately and to refine the localisation of the RS gene further. Furthermore, as all 14 families were informative for $D X S 207$ and as we observed no crossovers, the present study reduces further the possibility of genetic heterogeneity in RS. Future efforts to identify additional flanking and tightly linked markers in the RS subregion will now be facilitated by the availability of this informative polymorphism. This highly polymorphic and rapidly typed marker should greatly improve genetic counselling in RS families. It may also prove useful for mapping and diagnosis of other disease genes assigned to the Xp22.1-p22.2 region, in which informative markers are sparse. These include Coffin-Lowry syndrome (CLS), ${ }^{11} \mathrm{X}$ linked hypophosphataemic rickets (HYP), ${ }^{15}$ NanceHoran syndrome (NHS), ${ }^{16}$ and spondyloepiphyseal dysplasia tarda (SEDL). ${ }^{17}$

We are indebted to $\mathrm{Dr} J \mathrm{~L}$ Mandel for his critical reading of the manuscript and for helpful discussions. We are grateful to the ICRF reference library staff for the DXS207 cosmid clone c100 C02105, to the oligonucleotide services staff for efficient synthesis of primers, and to $S$ Vicaire for sequencing. We would also especially like to thank all the families and clinicians whose participation made this study possible. This work was supported by a grant

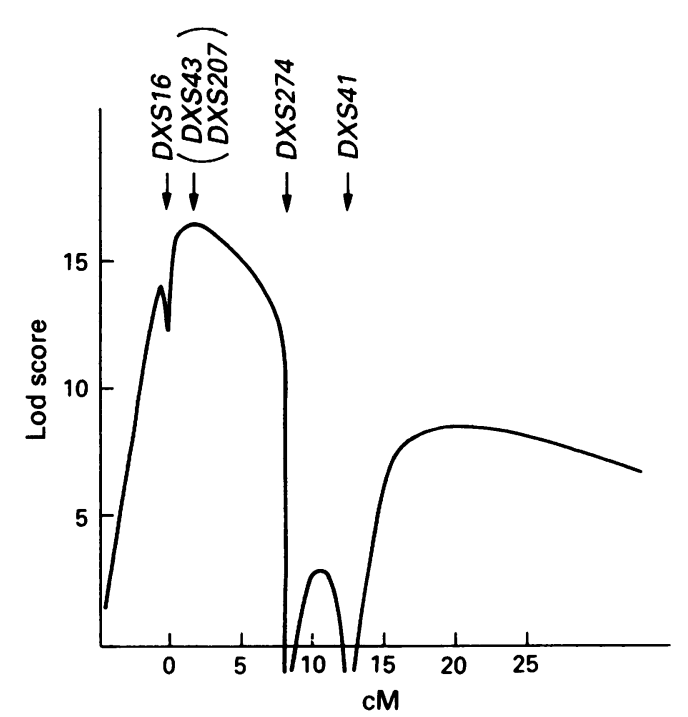

Multilocus $Z$ analysis for the placement of the $R S$ locus with respect to a fixed map of markers as described in the text. The locus DXS16 was arbitrarily placed at 0.0 
from the Association Française contre les Myopathies (AFM).

1 Deutman AF. The hereditary dystrophies of the posterior pole of the eye. Springfield, IL: Charles C Thomas, 1972.

2 Kaplan J, Pelet A, Hentati H, et al. Contribution to carrier detection and genetic counselling in $\mathrm{X}$ linked retinoschidetection and genetic counselling
sis. $\mathcal{F M e d}$ Genet 1991;28:383-8.

3 Condon GP, Brownstein S, Wang NS, Kearn AF, Ewing CC. Congenital hereditary (juvenile $X$ linked) retinoschisis. Arch Ophthalmol 1986;104:576-83.

4 Wieacker P, Wienkert TF, Dallapicolla B, Bender K, Davies K, Ropers H. Linkage relationships between retinoschisis, $\mathrm{Xg}$ and a cloned DNA sequence from the distal short arm of the X chromosome. Hum Genet 1983;64:1435.

5 Alitalo T, Forsius H, Kärnä J, et al. Linkage relationships and gene order around the locus for $\mathrm{X}$ linked retinoschisis. Am f Hum Genet 1988;43:476-83.

6 Dahl N, Goonewardena P, Chotal M, Anvret M, Pettersson U. DNA linkage analysis of $\mathrm{X}$ linked retinoschisis. Hum Genet 1988;78:228-32.

7 Alitalo T, Kruse TA, de la Chapelle A. Refined localization of the gene causing $\mathrm{X}$-linked juvenile retinoschisis. Genoof the gene causing $X-1 i c s$ 1991;9:505-10.
mics

8 Sieving PA, Bingham EL, Roth ML, et al. Linkage relationship of X-linked juvenile retinoschisis with Xp22.1p22.2 probes. Am $\mathcal{f}$ Hum Genet 1990;47:616-21.

9 Gellert G, Petersen J, Krawczak M, Zoll B. Linkage relationship between retinoschisis and four marker loci. Hum Genet 1988;79:382-4.
10 Alitalo T, Kruse TA, Ahrens P, Albertsen HM, Eriksson AW, de la Chapelle A. Genetic mapping of 12 marker loci in the Xp22.3-p21.2 region. Hum Genet 1991;86:599-603.

11 Biancalana V, Briard ML, David A, et al. Confirmation and refinement of the genetic localisation of the Coffin-Lowry syndrome locus in Xp22.1-p22.2. Am f Hum Genet 1992;50:981-7.

12 Oberlé I, Camerino G, Kloepfer C, et al. Characterisation of a set of $X$ linked sequences and of a panel of somatic cell hybrids useful for the regional mapping of the human $X$ chromosome. Hum Genet 1986;2:43-9.

13 Lathrop GM, Lalouel JM, Julier C, Ott J. Multilocus linkage analysis in humans: detection of linkage and estimation of recombination. Am $\mathcal{f}$ Hum Genet 1985;37:482-98.

14 Nizetic D, Zehetner G, Monaco AP, Gellen L, Young BD, Lehrach L. Construction, arraying, and high-density screening of large insert libraries of human chromosomes $\mathrm{X}$ and 21: their potential use as reference libraries. Proc Natl Acad Sci USA 1991;88:3233-7.

15 Thakker RV, Davies KE, Read AP, et al. Linkage analysis of two cloned DNA sequences, DXS197 and DXS207, in hypophosphatemic rickets families. Genomics 1990;8:18993.

16 Stambolian D, Lewis RA, Buetow K, Bond A, Nussbaum R. Nance-Horan syndrome: localisation within the region Xp21.1-Xp22.3 by linkage analysis. Am $\mathcal{F}$ Hum Genet 1990;47:13-19.

17 Szpiro-Tapia S, Sefiani A, Guilloud-Bataille $M$, et al. Spondyloepiphyseal dysplasia tarda: linkage with genetic markers from the distal short arm of the X chromosome. Hum Genet 1988;81:61-3. 